\title{
Robust stock option plans
}

\author{
Olaf Korn • Clemens Paschke • Marliese Uhrig-Homburg
}

Published online: 10 May 2011

(C) The Author(s) 2011. This article is published with open access at Springerlink.com

\begin{abstract}
The main purpose of this paper is to address the issue of robustness of stock option plans, which is essential for reliable accounting valuations. The introduction of the accounting standards SFAS 123R and IFRS 2 for executive stock options has led to an important change. As companies are now forced to value their stock options at grant date for accounting purposes, the robustness of prices against the choice of certain valuation models and input parameters has become a very important issue. We address this issue by first analyzing certain building blocks of existing stock option plans with regard to their robustness properties. Based on our analysis, we then show how robustness of stock option plans can be achieved. The resulting stock option plans are both transparent in structure and reasonable in respect to the incentives they provide in order to increase shareholder value. We therefore conclude that stock options can be reliably expensed, if the corresponding plans are properly designed.
\end{abstract}

Keywords Stock option plans $\cdot$ Robustness $\cdot$ Accounting valuation · Corporate governance

JEL Classification $\mathrm{J} 33 \cdot \mathrm{G} 13 \cdot \mathrm{M} 41$

O. Korn $(\bowtie)$

Georg-August-Universität Göttingen and Centre for Financial Research Cologne (CFR),

Platz der Göttinger Sieben 3, 37073 Göttingen, Germany

e-mail: okorn@uni-goettingen.de

C. Paschke

Hansaallee 136, 60320 Frankfurt, Germany

e-mail: cpaschke@whu.edu

M. Uhrig-Homburg

Karlsruhe Institute of Technology (KIT), 76049 Karlsruhe, Germany

e-mail: uhrig@kit.edu 


\section{Introduction}

Accounting rules for executive stock options have changed substantially recently and moved towards a "fair value accounting" approach, both under US-GAAP and IFRS. ${ }^{1}$ These changes have severe consequences. The former regulation in the $\mathrm{US}^{2}$ allowed to expense just the option's intrinsic value and distinguished between plans with known exercise price (fixed plans) and plans with unknown exercise price, such as indexed options (variable plans). For fixed plans, expenses were only considered at the time when the plan was granted. Thus, the accounting treatment clearly favored plain vanilla at-the-money call options, where no expenses would ever occur. Under the new rules, however, there is no longer such a clear accounting-driven advantage for these types of plans. Hence, plan designers are expected to put more emphasis on the incentive effects of executive stock options, which might lead to more diversity and a more complex structure of plans. One indication of such a tendency has become apparent in Germany. Here, historically accounting rules did not favor a certain type of plan and we have already observed many different kinds of particularly complex plan designs. Apart from possible changes in the diversity and complexity of stock option plans, a major consequence of "fair value accounting" is the central importance of valuation models. As market prices of comparable option contracts are mostly unavailable, ${ }^{3}$ model prices have to be used. The valuation of stock option plans raises a range of different problems. Firstly, standard no-arbitrage option pricing models might not be appropriate. Although we take the shareholders' perspective and interpret the option price as an opportunity cost that would arise if the options were traded in the market, we cannot ignore the behavior of managers who receive the options. Recipients of stock option plans are restricted from selling or hedging their options. Since these options usually allow for early exercise after some vesting period, such restrictions might cause an exercise behavior that violates the assumptions of standard no-arbitrage models. ${ }^{4}$ As a result, the firm's "opportunity cost" is wrongly quantified according to standard models. Secondly, the increasing complexity of stock option plans might result in valuation problems that are difficult to solve, even within the standard no-arbitrage framework. In particular, one might need to rely on numerical valuation methods which are subject to approximation errors and make it more difficult to verify the results. Finally, even if valuation models provide reliable values in principle, these models need input parameters, such as volatility and future dividends, which are not directly observable and therefore must be estimated. Stock option plans usually have a long time to maturity, and therefore, estimation errors can have an important impact on the resulting value.

Each of the above-mentioned problems of valuation strongly raises the question as to how robust the actual model prices of stock option plans are. In this paper, we mainly concentrate on the third problem. However, we will see that all three problems are interrelated. For our purposes, we define robustness as a low sensitivity of an option's price with respect to the pricing model's input parameters that have to be estimated, such as the

\footnotetext{
${ }^{1}$ Compare the accounting standards SFAS 123R of 2004 and IFRS 2 of 2004. Jaggi et al. (2010) provide a perspective on the future of fair value accounting after the financial crisis.

2 Compare APB Opinion 25 of 1972, whose intrinsic-value method was still permitted under the original SFAS 123.

3 An interesting exception is the Finnish market, where firms can list their stock option plans on the stock exchange. However, listing occurs only after the options have vested. See Ikäheimo et al. (2006).

4 Empirical evidence on "too" early exercise is provided e.g. by Hemmer et al. (1996), Huddart and Lang (1996), Bettis et al. (2005), and Brooks et al. (2007).
} 
volatility, the future dividend yield, or the interest rate. If stock option plans are not robust, the reliability of their accounting values would be questionable. This would by itself call the entire approach to "fair value accounting" of stock option plans into question.

In addition, mispricing would not necessarily occur by chance, for example, due to unavoidable estimation errors. If a stock option plan is not robust, it provides opportunities for concise manipulation. It has been argued in the literature that certain design elements of stock option plans provide examples of managerial self-dealing. ${ }^{5}$ Robustness is a feature of stock option plans that potentially protects shareholders against self-dealing by managers, as it makes it more difficult to camouflage a plan's true value. A better understanding of the robustness properties of stock option plans could provide a basis for empirical tests of such a hypothesis. Moreover, one could empirically investigate if firms with better governance structures grant more robust compensation packages.

Our paper is closely related to the literature on the valuation of stock option plans. Major issues of this literature are certain special features of executive stock options, namely, vesting periods, forfeiture, and early exercise. In particular, the problem of early exercise has received much attention. It has been dealt with by either integrating utility maximizing elements into the valuation model, or, by specifying an exogenous exercise threshold. ${ }^{6}$ Another strand of the valuation literature has dealt with non-standard forms of executive stock options. Hemmer et al. (1998) and Dybvig and Loewenstein (2003) have considered reload options and Brenner et al. (2000) have dealt with resettable options. ${ }^{7}$ Johnson and Tian (2000b) have analyzed indexed options and Câmara (2001) has looked at the valuation and the incentive effects of options which can only be exercised if an outperformance compared to a reference portfolio is achieved. In another paper, Johnson and Tian (2000a) analyze and compare six different types of non-standard stock option plans, namely premium options, performance-vested options, resettable options, purchased options, reload options, and indexed options.

The literature on the valuation of stock option plans has provided (sometimes as a byproduct) important results on the robustness issue: Ammann and Seiz (2004) consider the impact of model choice on an option's value, by comparing different valuation models. An important result of their study states that no-arbitrage option pricing models and utility maximizing models lead to very similar values if they are calibrated to the same expected lifetime of the option. Bettis et al. (2005), who calibrate different valuation models using an extensive data set of option exercises of corporate executives, arrived at the same conclusion, stating ${ }^{8}$ : "For determining the costs of shareholders of granting ESOs, we show that simply adjusting the maturity of a tradable American option reflecting the expected time of exercise produces valuations that are close to those computed from the more elaborate utility based model". These results suggest that the values of stock options plans are quite robust with respect to the model choice. However, the effective time to maturity needs to be known to determine the value precisely.

\footnotetext{
5 See e.g. Bebchuk and Fried (2003) and Bebchuk et al. (2002). Sautner and Weber (2011) provide empirical support for the self-dealing hypothesis by showing that when governance structures are weak, stock option plans are designed in a way that is favored by managers.

${ }^{6}$ Corresponding models have been developed and analyzed by Kulatilaka and Markus (1994), Rubinstein (1995), Carpenter (1998), Hull and White (2004), Ammann and Seiz (2004), Cvitanić et al. (2008), and Brisley and Anderson (2008).

7 Yang and Carleton (2010) analyze the repricing of executive stock options under new accounting rules in an optimal contracting setting.

${ }^{8}$ See Bettis et al. (2005), p. 469.
} 
Rubinstein (1995) also focuses strongly on the aspect of robustness, especially with respect to input parameters. Concentrating on an at-the-money call option (traditional or standard stock option plan), he analyzed the sensitivity of option prices to volatility, dividend yield, early exercise, delayed vesting, and the forfeiture rate, among other things. As his results show, a traditional stock option plan is strongly non-robust with respect to estimation errors, resulting in price differences of up to $60 \%$ for reasonable parameter variations.

Johnson and Tian (2000a) compare different plans with respect to their sensitivity to volatility changes, changes in the dividend yield, and changes in the stock price. ${ }^{9}$ In particular, they have shown that traditional call options have lower deltas and vegas than indexed options, although they are more sensitive to dividend yield changes. Johnson's and Tian's selection of stock option plans was based on the Conference Board Report of 1992. New design elements have emerged, however, in practice recently, particularly combinations of both absolute and relative performance targets, ${ }^{10}$ as well as barriers and caps. These elements are expected to have an important impact on a stock option plan's robustness.

The literature has provided important insights into the robustness of executive stock option plans, however, the focus has been on the characteristics of different plan designs that have existed in practice or which were suggested. Very little attention has been paid to the question of how different design elements can be combined in order to improve robustness of plans. This paper is the first that systematically deals with this important issue. Our main conclusion is that the construction of robust plans is indeed possible and that these plans possess reasonable incentives to increase shareholder value. The key to this result is the use of European style options instead of American or Bermudan style options. The former are able to resolve different problems related to the robustness issue. Firstly, the problem of determining the optimal exercise strategies of corporate executives disappears. Secondly, analytical pricing formulas become applicable, which facilitates the verification of model prices by outsiders and improves the transparency of the valuation process. Finally, robustness with respect to input parameters can be achieved more easily. In particular, the use of caps allows us to solve the problem of parameter robustness with respect to volatility, by explicitly constructing vega-neutral plans. In summary, our results suggest that "fair value accounting" introduces certain robustness problems, although at the same time, eliminating the bias towards a certain type of plan, it can offer the opportunity to design plans which actually minimize the robustness problem.

The remaining part of this paper is structured as follows: In Sect. 2 we begin by introducing some examples of real stock option plans. These show the variety of different features that constitute real plans and provide a first impression on the robustness of alternative plan structures with respect to variation of input parameters. In Sect. 3, that follows, we analyze different elements of stock option plans separately and quantify their effect on a plan's robustness. Based on this analysis, Sect. 4 discusses how robust plans could be constructed and analyzes some of their properties. Our conclusions are presented in Sect. 5.

\footnotetext{
9 As the main focus of Johnson's and Tian's (2000a) work is the incentive effect of different kinds of stock option plans, the stock price sensitivity is very important.

${ }^{10}$ See Bettis et al. (2010) for an empirical study on the use of stock option plans with performance contingent vesting conditions.
} 


\section{Examples of existing stock option plans}

To exemplify the variety and complexity of stock option plans, a selection of stock option plans is presented in this section. All of these examples are taken from Germany, as historically, accounting rules in Germany did not favor stock option plans of a certain type of design (such as the fixed plans in the US). Thus, German stock option plans could provide prototypes for the kind of design we will see in the future.

With respect to their performance targets, stock option plans can be assigned to one of three groups: The first group sets only absolute performance targets compared to historical share prices. Most plans in the US belong to this group. The second group requires only relative performance targets, whereupon share price performance is measured relative to specific comparable shares or indices. Finally, the third group combines absolute and relative performance targets.

To illustrate different design principles of stock option plans and get an initial impression of the price sensitivity with respect to volatility, dividend, interest rate, and stock price changes, we provide concrete examples for each specific group of plans. All of these plans come from companies which are included in the DAX 30, Germany's major blue chip stock index ${ }^{11}$ and contain the main design features associated with stock option plans in Germany.

Linde AG has started the Linde Management Incentive Program in 2002. As this plan specifies only an absolute performance target, it belongs to the first group. Here, call options with an exercise price of $20 \%$ above the stock price were issued, i.e., out-of-themoney calls. These options had an initial time to maturity of 7 years and early exercise was not allowed during a vesting period of 2 years. The Deutsche Boerse AG Option Plan is an example of the second group of plans, with purely relative performance targets. The options pay the difference in performance between the stock price and a benchmark index, which is the Dow Jones STOXX Technology Index. Hence, they are initially at-the-money exchange options. The initial time to maturity is 5 years with a vesting period of 3 years.

An example of a combination of relative and absolute performance targets which belongs to the third group is the BASF Stock Option Program 2005, issued by the chemical firm BASF. Within this plan recipients receive an equal amount of two sub-plans, called rights A and B. Right A is an at-the-money option with an absolute exercise threshold of $30 \%$ above the stock price at grant date and with a cap equal to $100 \%$ of the stock price at grant date. Right B is a dividend protected at-the-money exchange option against the MSCI Chemicals Index. It has an additional cap equal to the difference between the share price at exercise and the face value of the share. The options have an initial time to maturity of 8 years and a vesting period of 2 years. Rights A and B can only be exercised jointly and the total value is additionally capped at a level of 2.5 times the strike price. The BASF plan has substantial additional complexity, due to the joint exercise rule and the different caps. Such caps are indeed a common feature of stock option plans in Germany, which might be justified as a protection to shareholders against extraordinary and unforeseen events in the stock market. $^{12}$

\footnotetext{
11 The DAX 30 comprises 30 companies, 22 of which had installed a stock option plan to compensate executives in 2005. Of the corresponding 22 plans, six belong to the first group, four to the second group, and twelve to the third group.

12 See the reasoning in the German Corporate Governance Code (Regierugskommission Deutscher Corporate Governance Kodex (2005), p. 7), which recommends caps in stock option plans.
} 
A further example of a combination of absolute and relative performance targets is the Group Incentive Plan of the insurance company Allianz AG. Unlike the BASF program, the relative performance is implemented through a barrier option rather than an exchange option. The plan contains an at-the-money call with 7 years to maturity and a vesting period of 2 years. The absolute performance target has a threshold at maturity that is $20 \%$ above the strike price. The plan also contains a cap that is $150 \%$ above the strike price. The relative performance target states that the option can only be exercised if a benchmark index (Dow Jones Europe STOXX Price Index) has been outperformed at least once for a period of five consecutive trading days.

Based on the above examples, we want to offer a first impression of input parameter robustness and incentive effects of various designs. To do so, we need appropriate robustness measures, valuation models, and base case input parameters.

Robustness refers to the sensitivity of a stock option plan's value (model price) to changes in the major "unknowns" of option pricing, volatility, dividend yield, and riskfree interest rate. Plans with a lower sensitivity to volatility, dividend yield, and risk-free interest rate are considered to be more robust. Incentive effects ${ }^{13}$ are approximated by the sensitivity of a plan's value to a change in the stock price. Plans with higher sensitivities to changes in the stock price are considered to provide stronger incentives.

As a simple way to measure sensitivity we rely on the slope of a plan's value function with respect to the parameter under consideration. To ensure comparability across plans, we standardize their values to an amount of $€ 100$ by choosing the number of options granted for each plan appropriately. The reason for this is that firms can scale the number of options they grant so that they reach a specified total value of the plan. Therefore, different plans should be compared using this total value.

To obtain a value function and the corresponding sensitivity measures for each plan, we need a valuation model that can deal with the various absolute and relative performance targets of the four plans and the possible early exercise after the end of the vesting period. Our choice is a three-dimensional tree model ${ }^{14}$ with 300 time steps. The advantage of this model lies in its relatively simple structure and its capability to price all different stock option plans within a unified framework. It is clearly a limitation of the model that it does not capture certain characteristics of stock returns, like large jumps or a stochastic volatility. ${ }^{15}$ However, as the accounting valuation of stock option plans by German firms relies predominantly on simple closed form valuation formulas or tree models, it seems most relevant to base the robustness analysis on such a simple model.

Finally, we have to choose a set of reasonable base case input parameters, i.e., stock and index return volatilities, return correlations, dividend yields, and interest rates. To our knowledge, there is no industry standard to obtain parameter values. However, one practical rule is to estimate volatilities, correlations and dividend yields from historical data that reaches as far back into the past as the maturity date of the options lies in the future. For example, if a plan has a time to maturity of 7 years, like the plans by Linde and Allianz, the estimation period would consist of the 7 years preceding the valuation date.

\footnotetext{
${ }^{13}$ Of course, incentive effects could be quantified within the framework of a particular principal agent model. However, as we make no attempt to optimize incentive schemes, we employ a simple and general measure, as was used e.g. by Johnson and Tian (2000a). The extensive literature on optimal equity based compensation contracts is surveyed e.g. by Core et al. (2003) and Hall and Murphy (2003).

14 See "Appendix 1" for details.

15 Bakshi et al. (1997) and Chen and Lee (2009) provide empirical evidence on how these characteristics affect the performance of different option pricing models.
} 
Table 1 Historical parameter estimates for four existing stock option plans

\begin{tabular}{|c|c|c|c|c|c|c|c|c|}
\hline \multirow[t]{2}{*}{ Parameter } & \multicolumn{2}{|l|}{ Linde } & \multicolumn{2}{|c|}{ Deutsche Boerse } & \multicolumn{2}{|c|}{ Allianz } & \multicolumn{2}{|l|}{ BASF } \\
\hline & Stock & Index & Stock & Index & Stock & Index & Stock & Index \\
\hline Return volatility & $24 \%$ & - & $34 \%$ & $24 \%$ & $41 \%$ & $18 \%$ & $26 \%$ & $18 \%$ \\
\hline Return correlation & - & & 0.50 & & 0.75 & & 0.80 & \\
\hline Dividend yield & $2.3 \%$ & - & $1.8 \%$ & $1.7 \%$ & $2.5 \%$ & $2.8 \%$ & $3.5 \%$ & - \\
\hline Interest rate & $3.1 \%$ & & - & & $3.1 \%$ & & $3.3 \%$ & \\
\hline
\end{tabular}

This table shows historical parameter estimates for the example stock option plans. Return volatilities and return correlations are estimated from monthly data over the estimation periods. Dividend yields refer to average yearly yields. The estimation periods are January 2003 to December 2009 (Linde, Allianz), January 2002 to December 2009 (BASF), and January 2005 to December 2009 (Deutsche Boerse). Interest rates refer to the term structure of German government bonds at the end of 2009. For Linde and Allianz, we use the interest rate for a maturity of 7 years. For BASF, the interest rate for a maturity of 8 years is used

For most stock option plans, the valuation date is the last day of the year. ${ }^{16}$ For the estimation of our reference parameters, we use the valuation date December 31st 2009 and the corresponding historical estimation periods. Volatilities and correlations are estimated from monthly returns. Dividend yields are the average yearly yields ${ }^{17}$ over the estimation periods, and interest rates refer to the term structure of German government bonds at the end of 2009. The resulting parameter estimates are given in Table 1.

A first interesting robustness issue is how many parameters are needed to value the different plans. The more parameters we require, the more potential estimation problems can arise. Some particular features of the four example plans affect the number of input parameters. Most notably, the stock option plan by Linde has no relative performance target and therefore needs no information on index return volatility or dividends. The plan by Deutsche Boerse can formally be seen as an exchange option, which means that interest rates do not enter into the valuation. ${ }^{18}$ Finally, Right $\mathrm{B}$ of the BASF plan is protected for dividend payments. Therefore, the dividend yield of the reference index is not needed. The dividend yield of the BASF stock is required to value Right A of the plan, however.

Table 2 provides the sensitivity measures based on the historical parameter estimates of Table 1. The slope values which are shown can be interpreted as follows: As an example, take the Linde stock option plan. If volatility increases from 24 to $25 \%$, the option's price goes up from 100 to 105.11 . Similarly, an increase in the dividend yield from 2.3 to $3.3 \%$, leads to a price decline from 100 to 84.95 . An increase in interest rates from 3.1 to $4.1 \%$ corresponds to a price increase from 100 to 109.98 . Finally, a number of 2.62 for the incentive effect means that a $1 \%$ increase in the stock price would lead to a price increase of the plan from 100 to 102.62 .

The results of Table 2 show that the robustness of different plans can vary substantially. Some of these differences follow directly from certain design features of the plans. The plan by Deutsche Boerse shows no interest rate sensitivity, because interest rates do not enter the valuation model. The same holds for Right B of the BASF plan, which is another exchange option. Therefore, the interest rate sensitivity of the BASF plan stems

\footnotetext{
${ }^{16}$ If stock option plans are settled with cash, as the plans by Allianz, Deutsche Boerse, and BASF, they have to be valued at the balance sheet date. The balance sheet date usually coincides with the end of the calender year.

17 Note that dividends are paid only once a year in Germany.

18 Compare also the pricing formula for European exchange options derived by Margrabe (1978).
} 
Table 2 Robustness and incentive effects of four existing stock option plans for historical parameter estimates

\begin{tabular}{llccc}
\hline Plan & \multicolumn{2}{l}{ Robustness to changes in } & Incentive effect \\
\cline { 2 - 4 } & Volatility & Dividend yield & Interest rate & \\
\hline Linde & 511 & $-1,505$ & 998 & 2.62 \\
Deutsche Boerse & 233 & -956 & 0 & 2.40 \\
Allianz & 157 & -699 & 305 & 1.59 \\
BASF & 241 & -445 & 202 & 2.60 \\
\hline
\end{tabular}

This table shows the slopes of the plans' value functions with respect to volatility, dividend yield, interest rate, and stock price, respectively. Plan values are standardized at $€ 100$ for the historical parameter estimates of Table 1. The slope values have the following interpretation: If, for example, the return volatility of the Linde stock increases from 24 to $25 \%$, the option's price goes up from 100 to 105.11. Similarly, an increase of the dividend yield from 2.3 to $3.3 \%$ leads to a price decline from 100 to 84.95 . An increase in interest rates from 3.1 to $4.1 \%$ corresponds to a price increase from 100 to 109.98 . Finally, a number of 2.62 for the incentive effect means that a $1 \%$ increase in the stock price would lead to a price increase of the plan from 100 to 102.62

exclusively from Right A, which explains the relatively small value of 202 . The relatively low dividend yield sensitivity of the BASF plan follows from the dividend protection of Right B. Other major differences in robustness between plans, in particular with respect to the stock return volatility, need further examination.

The differences in Table 2 might not solely be due to differences in plan designs but could potentially be affected by the different parameter values that we used to value each plan. Therefore, we choose a common base case parameter set and recalculated all sensitivity measures based on this common set. Concretely, we choose a stock return volatility of $25 \%$ p.a., an index return volatility of $15 \%$, a correlation of 0.7 between stock and index returns, a dividend yield of $2 \%$ p.a. for both the stock and the reference index, and a riskfree rate of $3 \%$ p.a. These parameter values lie in the range of the historical estimates. Note, however, that relatively low volatilities have been chosen, because the time of the financial crisis, which falls in our estimation period, led to exceptionally high historical estimates. The robustness results for the common base case parameter set are presented in Table 3. As a point of reference we also consider an at-the money call.

The results of Table 3 confirm that stock option plans can be highly non-robust. Apparently, the reaction to volatility changes strongly depends on the design of the stock option program. The prices of the plans of Linde AG and Deutsche Boerse AG react much stronger to volatility changes than our reference point, the traditional at-the-money call. In contrast, the sensitivity of the plan of Allianz AG is less than that for the first two plans. The plan is, however, still less robust than the traditional call. Surprisingly, the plan of BASF AG is the most robust one with respect to volatility changes. This plan shows even less sensitivity than the at-the-money call. Besides the basic plan structure itself, possible explanations for the differences could be the role of caps or the joint exercise of sub-plans. The effect of theses design features will be further explored in the next section. In comparison with Table 2, the most striking result is that the robustness of the plans by Deutsche Boerse and Allianz is strongly reduced in general. This finding is due to the fact that for these stocks the base case volatility is clearly smaller than the historical volatility estimate used in Table 2. Therefore, the dependence of robustness on the level of volatility also deserves further investigations. 
Table 3 Robustness and incentive effects of four existing stock option plans and an at-the-money call option for a common base case parameter set

\begin{tabular}{|c|c|c|c|c|}
\hline \multirow[t]{2}{*}{ Plan } & \multicolumn{3}{|c|}{ Robustness to changes in } & \multirow[t]{2}{*}{ Incentive effect } \\
\hline & Volatility & Dividend yield & Interest rate & \\
\hline At-the-money Call & 341 & $-1,366$ & 823 & 2.33 \\
\hline Linde & 480 & $-1,513$ & 984 & 2.53 \\
\hline Deutsche Boerse & 445 & $-1,481$ & 0 & 3.70 \\
\hline Allianz & 344 & $-1,283$ & 764 & 2.21 \\
\hline BASF & 311 & -437 & 217 & 2.64 \\
\hline
\end{tabular}

This table shows the slopes of the plans' value functions with respect to volatility, dividend yield, interest rate, and stock price, respectively. Plan values are standardized at $€ 100$ for the base case scenario, characterized by a stock return volatility of $25 \%$ p.a., an index volatility of $15 \%$, a correlation of 0.7 between stock and index returns, a dividend yield of $2 \%$ p.a. for the stock, a dividend yield of $2 \%$ p.a. for the reference index, and a risk-free rate of $3 \%$ p.a. The slope values have the following interpretation: If the return volatility increases from 25 to $26 \%$, the price of the at-the-money call option, for example, goes up from 100 to 103.41. Similarly, an increase of the dividend yield from 2 to $3 \%$ leads to a price decline from 100 to 86.34. An increase in interest rates from 3 to $4 \%$ corresponds to a price increase from 100 to 108.23 . Finally, a number of 2.33 for the incentive effect means that a $1 \%$ increase in the stock price would lead to a price increase of the plan from 100 to 102.33

One might suspect that a low sensitivity of a plan with respect to volatility, dividend yield, and interest rate would render the plan unattractive from an incentives' perspective, as its sensitivity to stock price changes is reduced. The results of Table 3 , however, show no clear relation between volatility, dividend, and interest rate sensitivities on the one hand and stock price sensitivity on the other. For example, although Linde AG's plan is most sensitive to volatility and dividend changes, it also shows a very similar stock price sensitivity to BASF AG's, which is the most robust one with respect to a mis-specification of either volatility or dividend yield.

In summary, we have seen that real plans can have a large set of different design features. However, there is no indication that these design features are generally used to make plans more robust. What we observe is that different plans show big differences in robustness. Therefore, it is worthwhile searching for certain properties of a plan that may strongly reduce or increase robustness. In addition, it is also evident that a higher complexity of a plan does not necessarily lead to a higher sensitivity, as can be seen from BASF AG's plan. Instead, we have to look more closely at the different design elements to understand which elements are useful to improve robustness and which ones just make the plan overly complex.

\section{Robustness of stock option plans}

As a further step towards understanding the robustness of stock option plans, we investigate how single design elements of plans affect their robustness with regard to the input parameters volatility, dividend yield, and risk-free interest rate. For this purpose, we use the example plans presented in the previous section to pinpoint certain building blocks. We first differentiate between some basic plan structures and then add additional features, such as the joint exercise of sub-plans and caps. 


\subsection{Basic plan structures}

Our investigation of existing stock option plans revealed five basic plan structures:

- Traditional stock option plan: an at-the-money call option that can be exercised at any time after the end of a vesting period. Thus, the strike price $X$ equals simply the stock price $S_{0}$ at the grant date of that plan. This plan is widely used in the US and serves as the reference point for our analysis.

- Premium option: an out-of-the-money call, i.e., the strike price $X$ lies above the stock price $S_{0}$. The difference between these two prices determines the performance target. One way to set the performance target would be to require an appropriate risk-adjusted hurdle rate per year.

- Option with absolute exercise condition: a plan with a payoff equal to a traditional option, if an absolute performance goal is reached, and zero otherwise. In other words, we have a portfolio consisting of a premium option and a digital option that pays out the difference between $S_{0}$ and $X$ if the stock price at exercise exceeds $X$.

- Indexed option: an at-the-money option to exchange a reference portfolio (the index) for the stock of the company. The option is at the money if the index is normalized such that it equals the stock price at grant date.

- Relative performance vested option: a plan with a relative performance target, that is used as an exercise condition only. Formally, such a plan structure consists of an at-themoney up-and-in barrier call option with the price of a reference portfolio as stochastic barrier.

\subsection{Robustness of basic plan structures}

Figure 1 provides a first impression of the robustness of the different basic plans with respect to volatility ("vega", top of figure), the dividend yield ("dividend yield sensitivity", middle), and the risk-free interest rate ("rho", bottom). As in Sect. 2, the slope of a plan's value function is used to measure its parameter robustness. To construct Fig. 1, the base case parameters from Table 3 are used and we consider a time to maturity of 8 years and a vesting period of 2 years for all of the plans. In addition, for the premium option and the absolute performance vested option we assume that the strike price $X$ is $30 \%$ above the stock price $S_{0}$.

The upper part of Fig. 1 provides an illustration of the robustness with respect to volatility. On the x-axis, we see different levels of volatilities, which might represent different kinds of stocks, such as growth stocks or value stocks. Thus, when multiplying the "vegas" on the y-axis of Fig. 1 by 0.01 , as an example, the result can be interpreted as the percentage change in value of the stock option plan corresponding to a one percentage point estimation error in volatility. First, the resulting values are rather high in magnitude, given that an estimation error of only one percentage point for volatility is considered. Second, we see that the premium option clearly has the highest vega independent of the volatility level. In contrast, the indexed option has the lowest vega for very small stock return volatilities but once volatilities approach a medium or even high level, its vega exceeds the vegas of the traditional option, the option with absolute exercise condition, and the relative performance vested option. Third, it should be noted that the vega strongly depends on the volatility level. With exception of the indexed option, all basic plan structures show that robustness improves monotonically with volatility (decreasing vega), which generalizes the observations from the previous section. This result is in line with 


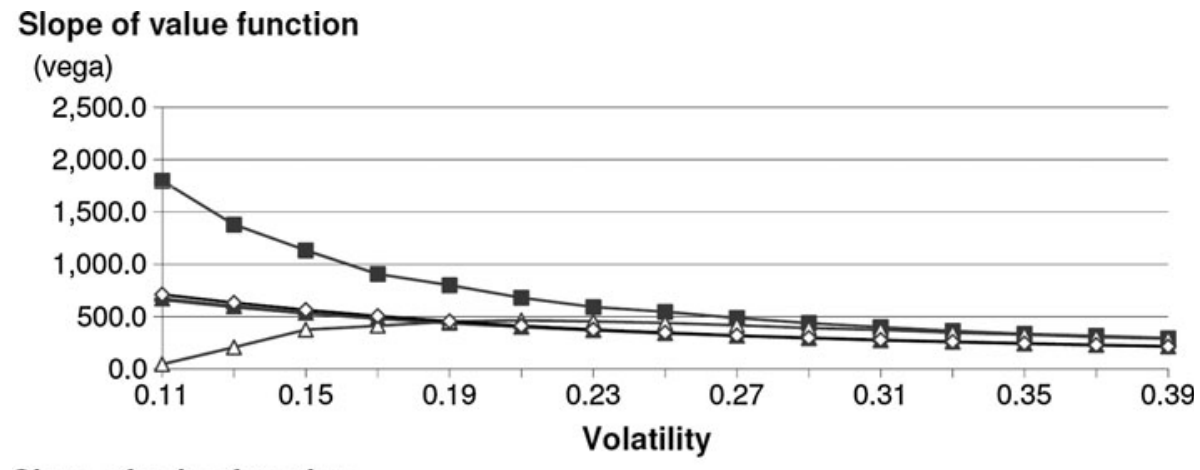

Slope of value function

(dividend yield sensitivity)

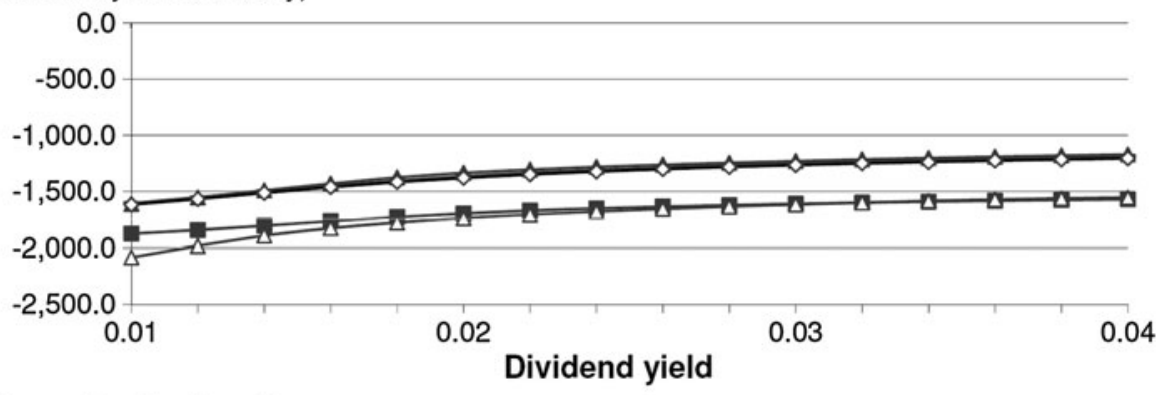

\section{Slope of value function}

(rho)

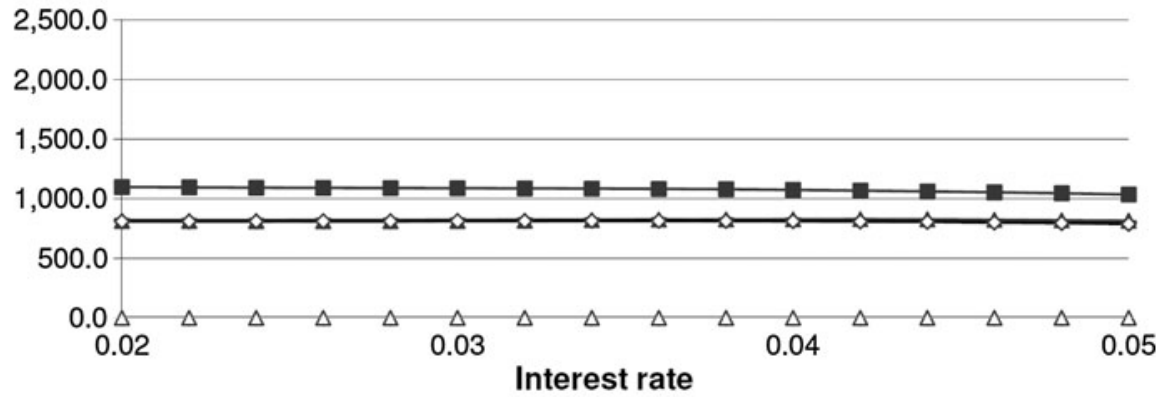

- Traditional option

$\rightarrow-$ Premium option

$\leadsto$ Relative performance vested option

$\_$Option with absolute exercise condition $\rightarrow-$ Indexed option

Fig. 1 Slopes of the plans' value functions with respect to volatility, dividend yield, and interest rate. This figure shows the slopes of the plan's value functions with respect to volatility, dividend yield, and interest rate for different levels of volatility, dividend yield, and interest rate. Plan values are standardized at $€ 100$. The additional parameter values are a stock return volatility of $25 \%$ p.a., a dividend yield of $2 \%$ p.a. for the stock, a dividend yield of $2 \%$ p.a. for the reference index, an index volatility of $15 \%$ p.a., a risk-free rate of $3 \%$ p.a., and a correlation between stock and index returns of 0.7 . The time to expiration equals 8 years and the vesting period equals 2 years

theoretical considerations. For example, in the Black-Scholes model, the price of a call option converges to the stock price if the product of the return variance and the time to maturity goes to infinity. Therefore, if the volatility or the time to maturity becomes larger 
and larger, the option should behave more and more like the stock. Since the stock itself is completely robust, we would expect the option to become more and more robust. At first sight, the non-monotonic behavior of the indexed option's vega is puzzling. However, we need to consider that for an exchange option the relevant volatility measure is the square root of the sum of the stock return variance and the index return variance minus two times the covariance. This volatility measure is a non-monotonic function of the stock return volatility, i.e., it decreases with increasing stock return volatility for small volatilities and increases for large volatilities.

With respect to the dividend yield, the effect of a one percentage point prediction error is quite substantial, leading to decreases in value of between 10 and $20 \%$. Moreover, we can distinguish between two groups of plans: the premium option and the exchange option fall under the first group, which is more sensitive to the dividend yield. The remaining three options, which are less sensitive to dividend yield changes, build the second group.

In addition, the interest-rate sensitivity "rho", given a one percentage point estimation error, varies heavily between plan structures, ranging from a value of zero to approximately $11 \%$. The premium option is the most sensitive, followed by the traditional option, the option with an absolute exercise condition and the relative performance vested option. The last three of these plans behave very similarly. Finally, as already mentioned in the previous section, the indexed option shows complete robustness with respect to the interest rate because the risk-free interest rate does not enter valuation models for exchange options.

Different conclusions can be drawn from our analysis so far. Firstly, the non-robustness of stock option plans with respect to volatility, dividend yield, and risk-free interest rate can be strong. Secondly, there is no single plan that dominates all other plans in terms of robustness if we take all the three input parameters into account. Finally, Fig. 1 suggests that the traditional option, the option with an absolute exercise condition and the relative performance vested option have very similar robustness properties, i.e., the additional exercise conditions have very little impact on robustness. A sensitivity analysis shows that this result holds for a broad range of parameter values. ${ }^{19}$ Thus, it is possible to concentrate on one of the three options, the natural choice being the traditional option, which is the simplest one.

\subsection{Additional design elements and robustness}

Existing option plans typically combine basic plan structures with additional elements such as caps, different vesting periods or joint-exercise requirements for sub-plans. How these elements affect the robustness of the plan structures is analyzed in the following subsections.

\subsubsection{Impact of joint exercise of sub-plans}

One design element of existing stock option plans is the joint exercise of sub-plans. Several German stock option plans such as those of BASF AG and Allianz AG combine options with absolute and relative performance targets into an options basket. A joint exercise condition forces the option's recipient to exercise options with absolute and relative performance targets simultaneously. If only one performance target is fulfilled at the time of exercise, the other option forfeits worthless, which reduces the likelihood of early exercise.

$\overline{19}$ See "Appendix 2" for details. 
The existence of joint-exercise features raises the question of how this feature impacts robustness. To provide some evidence on this issue, we consider a combination of a traditional option and an indexed option. For a wide range of parameter values, sensitivities with respect to volatility, dividend yield, and interest rate were calculated. ${ }^{20}$ These calculations show that the joint exercise of sub-plans has usually a small impact on robustness with respect to all sensitivity measures. Moreover, joint exercise even leads to higher sensitivities in most cases, i.e., it does not bring an improvement. For example, if we consider our base case parameters, joint exercise leads to a small increase of vega from 391 to 396 . However, a decline in robustness can be worse. For a volatility of $15 \%$, a dividend yield of $3 \%$, and a risk-free interest rate of 3\%, joint exercise leads to an increase of the dividend yield sensitivity from $-2,142$ to $-2,360$. Additional calculations for other combinations of sub-plans confirm these findings. If we combine, for example, an indexed option and an absolute performance vested option under the base case parameter scenario, all sensitivity measures increase when moving from separate exercise to joint exercise. If we consider in addition the real plan by BASF AG that involves additional complexity due to different caps on a sub-plan and the full plan, differences between joint exercise and separate exercise are very small. The only positive effect of joint exercise is a marginal reduction of vega from 319 to 311 . In conclusion, our calculations show no evidence for a substantial and systematic improvement of robustness due to a joint-exercise requirement of sub-plans.

\subsubsection{Impact of caps and vesting period}

If we consider European options, the introduction of a cap can be seen as adding a short position in an out-of-the money call option to the original long call position. Since the sensitivities with respect to volatility, dividend yield, and interest rate of long and short positions have opposite signs, the introduction of caps could lead to a significant increase in the robustness of such stock option plans.

To provide some evidence of these effects, a cap (strike price of the shorted call option) equal to two times the stock price at grant date is introduced for the traditional option and the premium option. Since the relevant volatility for indexed options is lower than the volatility of the underlying stock itself, for comparison purposes, the cap of the indexed option is set equal to the cap of the traditional option in terms of distance to stock price at grant date, measured by standard deviations. As a result, in the case of the indexed option, the maximum outperformance of the stock was set as 0.72 times the stock price.

Using our base case parameters, a time to maturity of 8 years and a vesting period of 2 years, we observe that caps have only a small effect on the parameter robustness of the stock option plans, which is surprising at first sight. To this end, Fig. 2 shows the vegas for the case with caps. Compared to the vegas for the case without caps, as shown in Fig. 1, we see very little difference. If we take for example a volatility of $25 \%$, the vega of the traditional option with cap equals 314 , instead of 341 without a cap.

The reason for the rather weak impact of caps on robustness lies in the American feature of the stock option plans. If stock prices rise, the cap will trigger early exercise and the short position in the call can never be in the money. Therefore, the shorted call position will never develop its full potential to improve the overall robustness of the plan, compared

${ }^{20}$ Table 5 in "Appendix 2" provides these results, showing relative differences between the sensitivity measures ("vega", "dividend yield sensitivity", and "rho") under joint exercise and under separate exercise of sub-plans. 


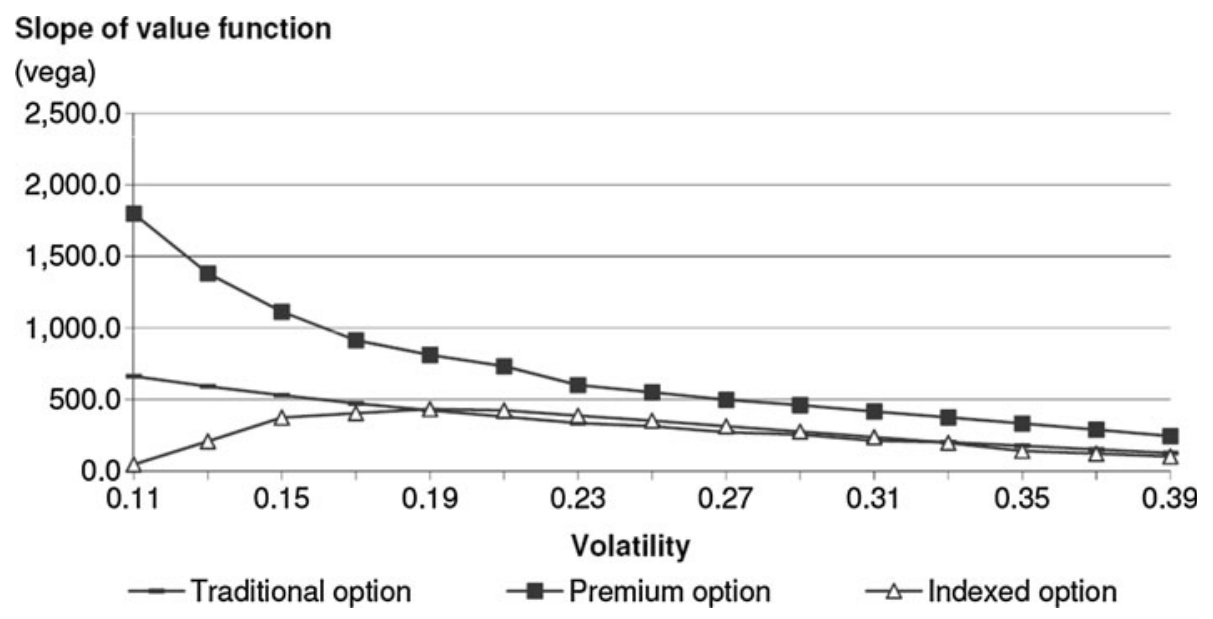

Fig. 2 Influence of caps on the vegas of different plan structures. This figure shows the slopes of the plans' value functions with respect to volatility for the case with additional caps. Plan values are standardized at $€ 100$. For the traditional option and the premium option, the cap equals two times the current stock price. For the indexed option, the maximum outperformance of the stock equals .72 times the current stock price. Further parameter values are a dividend yield of $2 \%$ p.a. for the stock, a dividend yield of $2 \%$ p.a. for the reference index, an index volatility of $15 \%$ p.a., a risk-free rate of $3 \%$ p.a., and a correlation between stock and index returns of 0.7 . The time to expiration equals 8 years and the vesting period equals 2 years

to European options. As an example, using our base case parameters, compare an at-themoney European option without a cap with the same option plus an additional cap at two times the current stock price at grant date. Such a cap reduces the option's value from 26.06 to 21.81 , or by approximately $18 \%$. In comparison, the otherwise identical American option suffers a price decrease of only $3 \%$.

As the examples show, the opportunity of early exercise can make caps ineffective to improve robustness. Therefore, we should consider the relation between caps and another feature of stock option plans, the length of the vesting period. As an illustration, let us consider the traditional option. For our base case parameters and a cap that equals two times the stock price at grant date, a vesting period of $2,4,6$, and 8 years is considered. Vega decreases from 314 to 178 if we lengthen the vesting period from 2 to 4 years and reaches a level of 103 for a vesting period of 6 years. If we lengthen the vesting period to 8 years, which means that the option is a European one, the option is almost vega-neutral (vega equals 13). In conclusion, this example shows that the robustness effects of the two design elements caps and vesting period cannot be judged in isolation. Moreover, it shows that caps have the potential to improve robustness considerably, if the vesting period is long enough.

\subsection{Example plans revisited}

After the analysis of the different basic plan structures and some additional design features, let us finally go back to our existing stock option plans in Table 3 . We have now gained a better understanding of the factors that drive the robustness of these plans. These factors can be summarized as follows: (i) Exchange options have no interest rate sensitivity, which explains the high robustness with respect to interest rates of the plans by Deutsche Boerse and BASF. (ii) The dividend protection of Right B of the plan by BASF makes this plan 
less sensitive to dividend yield changes. (iii) For the medium volatility level considered, options with absolute exercise condition have a higher robustness with respect to volatility than premium options and exchange options. Therefore, the plans by Allianz (option with absolute exercise condition) and BASF (partly option with absolute exercise condition) are more robust than the plans by Linde (premium option) and Deutsche Boerse (exchange option). (iv) The caps included in the plans by Allianz and BASF can only to a small part explain the relatively high robustness of these plans. (v) The joint-exercise feature of the plan by BASF can't explain robustness.

\section{Robust plans: an engineering approach}

\subsection{Construction of robust plans}

In this section we tackle the problem of how different design elements of stock option plans can be combined to improve robustness. As the literature and our results in the previous section have shown, stock option plans are rather non-robust with respect to volatility, dividend yield, and risk-free interest rate.

The granting of American or Bermudan options that allow for early exercise after the end of the vesting period is related to different robustness issues. If the exercise strategies of corporate executives are unknown, the effective time to maturity of the options, which has a strong impact on their value, becomes also unknown. Moreover, as we have seen in the previous section, early exercise reduces the potential of caps to improve robustness with respect to volatility. The vesting period is the design element of stock option plans which is most directly connected with the options' effective time to maturity and can be used to resolve the related problems. In the extreme, early exercise can be completely eliminated by equating the end of the vesting period with the expiration date of the option, i.e., by granting European options.

We furthermore have to acknowledge that there are some potential problems with the granting of European options. A possible objection might be that European options may give rise to particular incentive problems because the executive would concentrate on the firm's success at a single point in time. We believe, however, that these problems are not so special to European options and can be mitigated. Firstly, even with an American option, an executive might also concentrate her efforts on a single point in time, which is, however, unknown to others. Moreover, it might not be in the shareholders' interest that the executive just exploits a lucky situation when stocks are temporarily overvalued. Secondly, one could easily avoid the focus on a single time horizon by granting a portfolio of options with different times to maturity. The current practice of many firms to grant new executive stock options on a regular basis is effectively nothing else than giving employees a portfolio of options with different maturities.

Another issue is the practical problems that arise if an executive leaves the firm before the options can be exercised. Such problems already exist for American options if the leave happens within the vesting period. In this case, the options forfeit worthless. Although the granting of European options doesn't create a completely new problem, one has to admit that the problem is aggravated. When thinking about practical problems that arise from granting European options, one should also bear in mind that European options have already been granted. The stock option plans of the major German telecommunications firm, Deutsche Telecom AG and Metro AG, Germany's largest wholesaler, are examples of such practices. Moreover, at least in Germany, legislation has moved towards European 
options by requiring a minimum vesting period of 4 years since July 2009. ${ }^{21}$ Under previous law, the minimum vesting period was only 2 years.

The use of European options has clear advantages in terms of numerical tractability. The traditional option, the premium option, the option with an absolute performance target and the indexed option have straightforward analytical solutions under standard assumptions, if they are of European style. Even relative performance vested options can be valued analytically, along the lines of Heynen and Kat (1994). Moreover, Johnson and Tian (2000a) and Câmara (2001) have derived analytical valuation formulas for other non-standard options. In addition, caps can also be handled analytically without any further problems. The availability and applicability of analytical valuation formulas give rise to important benefits, especially with regard to accounting valuation. The accuracy of the resulting values is much easier to verify, communicate and audit, if analytical formulas are used. Therefore, the transparency of the valuation process is clearly improved.

The use of European options has also consequences for the robustness issue with respect to the choice of a risk-free interest rate. If the exercise strategy and thus the effective life time of the option is unknown, it is unclear which maturity should be chosen to select the interest rate. This problem can have a serious effect on the stock option plan's value if the term structure of interest rates is steep. However, when European options are granted and the lifetime of the option is known, then the choice of the interest rate is far less problematic, making robustness less important.

A second important input parameter of option pricing models is the dividend yield. Although most executive stock option plans are not protected against dividend effects, ${ }^{22}$ we see no good reason for this practice. ${ }^{23}$ On the contrary, one could argue that dividends are part of shareholder wealth which is created and management should not be penalized for providing them. Moreover, a missing dividend protection of executive stock option plans should not influence a firm's payout policy. ${ }^{24}$ Technically, dividend protection is not difficult to achieve: One either adjusts the strike price at any time a dividend is paid, or one uses a performance index as the underlying of the plan that captures all the benefits for shareholders. $^{25}$

The final remaining problem with respect to parameter robustness is volatility. The main design element that can deal with this problem is the use of caps. In the analysis to follow, we assume that a fully dividend protected European option is granted. In order to achieve robustness, we should set the cap (strike price of the short position in a call) at such a level that makes the whole stock option plan vega neutral. ${ }^{26}$ In order to determine the conditions under which this is possible, we have to take a look at the vega of a European call option,

\footnotetext{
21 See the "Gesetz zur Angemessenheit der Vorstandsvergütung (VorstAG)" of July 2009.

22 Plans also exist that are dividend protected. An example is given by Right B of BASF AG's stock option plan.

23 Historically, a reason has been that dividend protected plans were usually classified as variable plans for accounting purposes in the US, whereas traditional options without dividend protection were classified as fixed plans. Under the new accounting rules, however, this advantage of plans without dividend protection no longer exists.

24 Lambert et al. (1989) and Fenn and Liang (2001) provide empirical evidence that the provision of stock option plans which are not protected for dividends affects corporate payout policy.

25 Compare Arnold and Gillenkirch (2005) for a discussion and analysis of different forms of dividend protection.

26 Although complete robustness calls for a vega of zero, a positive vega could be beneficial in certain situations to mitigate underinvestment in risky projects. See e.g. Smith and Stulz (1985), Hemmer et al. (1999), Feltham and Wu (2001), and Brisley (2006).
} 


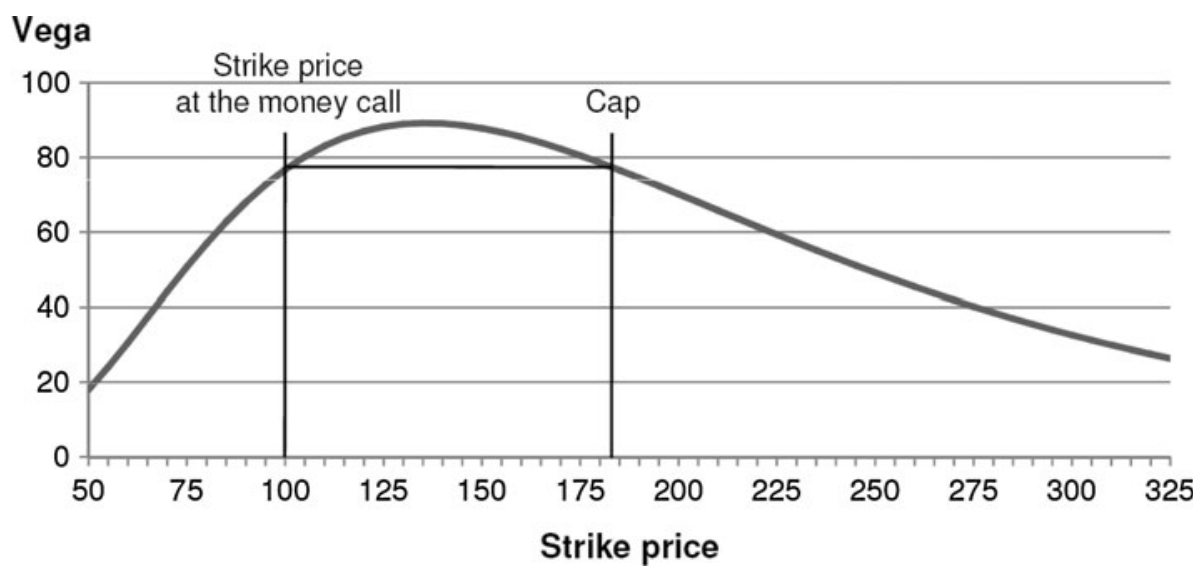

Fig. 3 Vega as a function of the strike price. This figure shows the theoretical vega of a single European call option as a function of the strike price. The calculations are based on the theoretical vega, as shown in Eq. 1, which results from the Black and Scholes model. The parameters used for the graph are a current stock price of $€ 100$, a volatility of $25 \%$ p.a., a risk-free rate of $3 \%$ p.a., and a time to maturity of 5 years

as given in Eq. $1,{ }^{27}$ where $S_{0}$ denotes the stock price at time zero (grant date), $X$ the strike price, $r$ the risk-free interest rate per year, $\sigma$ the stock return volatility, and $T$ the time to maturity.

$$
\begin{aligned}
& \text { Vega }=S_{0} \sqrt{T} N^{\prime}\left(d_{1}\right), \quad \text { with } \\
& N^{\prime}\left(d_{1}\right)=\frac{1}{\sqrt{2 \pi}} \mathrm{e}^{\frac{-d_{1}^{2}}{2}}, \quad \text { and } \quad d_{1}=\frac{\ln \left(S_{0} / X\right)+\left(r+\sigma^{2} / 2\right)(T)}{\sigma \sqrt{T}}
\end{aligned}
$$

The vega of a call option depends on the strike price $X$ and can be depicted as a function of the strike price. Figure 3 shows a corresponding graph, using an option with 5 years to maturity, ${ }^{28}$ a stock price of 100 , a stock return volatility of $25 \%$, and an interest rate of $3 \%$.

Figure 3 suggests how to construct vega-neutral stock option plans. Vega, as a function of the strike price, is at first increasing and then decreasing. This result explains our previous finding that a premium option has a higher sensitivity with respect to volatility changes than a traditional option. Moreover, it is easy to show that the vega function has a unique maximum at $S_{0} \mathrm{e}^{T\left(r+\frac{\sigma^{2}}{2}\right)}$. To obtain a vega-neutral plan, we first choose a strike price $X$ for the long call position that lies to the left of the maximum. In Fig. 3, for example, $X$ was chosen to be the current stock price of 100 . Next we determine the vega of the long call position and find the strike price $Y$ to the right of the maximum that leads to the same vega. If this strike price is found, we set the cap accordingly, since the vegas of the long call and the cap (a short call) will offset each other. Figure 3 shows graphically how to find the cap. Analytically, for $X<S_{0} \mathrm{e}^{T\left(r+\frac{\sigma^{2}}{2}\right)}$ the strike price $Y$ of the short call position is given by

\footnotetext{
27 See e.g. Hull (2009), p. 373f.

28 A period of five years to maturity is chosen instead of eight years, which we have used previously as our base case, as five years is a reasonable value for the expected lifetime of an American option with eight years to maturity. Thus, essentially, we aim to leave our base case parameters unchanged.
} 


$$
Y=\frac{S_{0}^{2}}{X} \mathrm{e}^{\left(2 r+\sigma^{2}\right) T}
$$

This analysis shows under which circumstances we will be able to construct a veganeutral, non-degenerate plan by means of caps. Firstly, if we set the strike price $X$ equal to the current stock price, i.e., if we consider a traditional option, we will always be able to find a cap to the right of $S_{0} \mathrm{e}^{T\left(r+\frac{\sigma^{2}}{2}\right)}$ that makes the plan vega neutral. Secondly, with premium options we are more limited. If we choose the risk-free interest rate as a hurdle rate to determine the strike price, once more, we will always be able to find an appropriate cap, although it might already be quite close to the strike price. If we choose a hurdle rate that lies well above the risk-free rate, we could end up with a value of $X>S_{0} \mathrm{e}^{T\left(r+\frac{\sigma^{2}}{2}\right)}$ and therefore would not be able to construct a completely vega-neutral plan through a short call with $Y>X$. This means that it might be impossible to obtain a fully robust plan if we require the full risk-adjusted cost of capital as the benchmark that determines the strike price.

Finally, we can also apply our analysis to indexed options. Since the valuation formula for these is structurally identical to the Black-Scholes formula, we simply have to reinterpret some parameters. Thus, for exchange options, $X$ would represent the index level at time zero and $\sigma^{2}$ would equal the sum of the stock return variance and the index return variance minus two times the covariance. Therefore, the relevant variance measure for indexed options would be smaller than the stock return variance if the index return variance is smaller than two times the covariance between stock returns and index returns, which would almost always be true. Since robustness with respect to volatility changes improves with the level of volatility, this smaller volatility explains the relatively low robustness of indexed options in comparison with traditional options that we have seen in Sects. 2 and 3 for medium and high stock volatility levels. Another issue of indexed options is that the interest rate does not enter into the valuation and has to be set to zero in all of the above formulas. Given the correct interpretation and specification of the parameters, we can conclude from our analysis that for at-the-money indexed options $\left(X=S_{0}\right)$ we can always find a cap that makes the whole stock option plan vega neutral.

\subsection{Properties of robust plans}

To get a better understanding of the specific properties of robust plans, let us first look at the cap with strike price $Y$, as shown in Eq. 2. As we can see, a comparative static increase in either $r, \sigma$, or $T$ leads to an increase of $Y$, i.e., the payoff of a robust stock option plan is capped at a higher level. Such a feature is both reasonable and desirable. Take for example the time to maturity, $T$. We would naturally think that a plan with a longer time to maturity should have a higher cap than an otherwise identical plan with a shorter time to maturity, since managers should deliver a better total performance if they were given more time. Similar arguments can also be applied to the risk-free interest rate and the volatility.

The comparative static analysis together with the numerical results of Sect. 3.2 (see in particular Fig. 1) show that robustness of stock option plans can be quite different for firms with different firm characteristics. For example, small firms are more likely to have a high return volatility and a low return correlation with the general stock market, which might translate into a low correlation with the benchmark index for indexed options. The first part of Fig. 1 in Sect. 3.2 highlights that a higher volatility improves robustness (lower vega) for all basic plan structures. Moreover, for the indexed option, a lower correlation with the 
reference index has an additional effect to reduce vega. In summary, we see that stock option plans of small firms are likely to be more robust because of higher volatilities and lower correlations with the reference index. The analytical results of Sect. 4.1 complement these findings. In particular, Eq. 2 shows that the cap level increases with growing volatility. Therefore, for small firms with high volatility, a cap is less important to achieve robustness. If volatility grows and return correlation with the benchmark index decreases, the design of a robust plan moves closer and closer towards a standard stock option plan or an indexed option without cap.

If a robust plan comes close to a standard stock option plan or an indexed option for high volatilities, it will also inherit the incentive effects of these basic plan structures. However, it is important to understand more generally whether robustness harms the incentive effects of stock option plans and the extent to which this will actually happen. To obtain some evidence on this issue, we look at the stock price sensitivity of two robust plan structures with either absolute or relative performance target. The first plan structure is a premium option with a strike price equal to the compounded current stock price, where the compounding is done with the risk-free rate over the life of the option. The second plan structure is an at-the-money indexed option. Using cap values according to Eq. 2, "Appendix 3" derives the initial deltas (at grant date) of the plans, which can be interpreted as elasticities of the stock option's value with respect to the stock price. These deltas take the following form:

$$
\text { Delta }=\frac{2 N\left(\frac{1}{2} \sigma \sqrt{T}\right)-1}{3 N\left(\frac{1}{2} \sigma \sqrt{T}\right)-2+\mathrm{e}^{\sigma^{2} T} N\left(-\frac{3}{2} \sigma \sqrt{T}\right)}
$$

For the premium option, $\sigma^{2}$ simply denotes the stock return variance. For the indexed option, $\sigma^{2}$ has to be interpreted as the stock return variance plus the index return variance minus two times the covariance.

Equation 3 shows that delta depends only on one parameter, the product $\sigma \sqrt{T}$. This finding allows us to plot delta as a function of $\sigma$ and $T$, as shown in Fig. 4. According to the figure, delta declines with increasing volatility and increasing time to maturity. In the limit, if either $\sigma$ or $T$ goes to infinity, delta approaches a value of one, which equals the delta of the stock itself. If either $\sigma$ or $T$ goes to zero, delta goes to infinity. ${ }^{29}$ Note that such a limiting behavior is not a specific feature of robust stock option plans, because the same results hold for premium options or indexed options without caps. We can draw two main conclusions from Eq. 3 and Fig. 4: Firstly, whatever the parameter values are, the initial incentive effect of a robust stock option plan will always be stronger than the incentive effect of a share of stock with the same value. This finding highlights a trade-off between robustness and incentive effects. An all-stock plan would be perfectly robust, as its value could be calculated from current market prices only. However, as our analysis shows, the incentive effect would be lower. Secondly, if we compare robust premium options with robust indexed options, indexed options always provide a stronger incentive effect if the index return variance is smaller than two times the covariance between stock returns and index returns. This latter condition should almost always be fulfilled in practice.

Similarly, we can also derive analytical expressions for the deltas of the plans at some later point in time $t$. Besides $t$ and the maturity $T$, the delta of the indexed option depends only on the realized stock return normalized to the index level at grant date and on the corresponding volatility. Of course, an extreme change in the stock price significantly

${ }^{29}$ See "Appendix 3" for a proof of the limiting behavior of delta. 


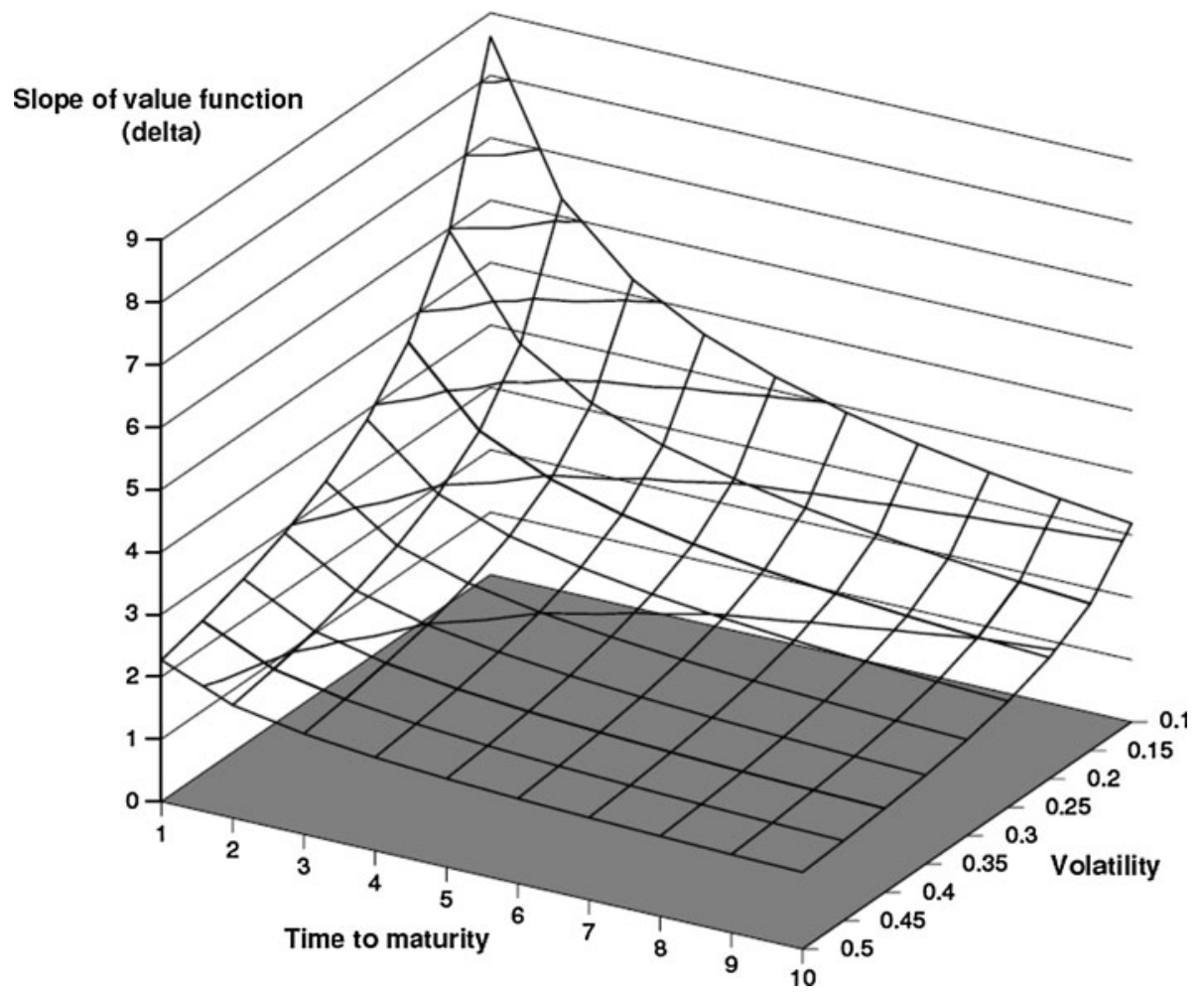

Fig. 4 Influence of volatility and time to maturity on the initial delta of a robust premium option (robust indexed option). This figure shows the theoretical initial delta of a robust premium option (robust indexed option) as a function of the volatility and the time to maturity. The calculations are based on the theoretical initial delta, as shown in Eq. 3, which is derived in "Appendix 3". Note that the initial delta depends exclusively on the parameters volatility and time to maturity

affects the plan's delta. However, when focusing, for example, on a move of one standard deviation or below, the resulting deltas are still fairly high. Overall, our findings show that the cap has not destroyed the incentive effects of the options. We still have a delta which is well above one for reasonable scenarios.

\section{Conclusions}

In this paper we have addressed the issue of robustness of stock option plans, which is essential for reliable accounting valuations. We have shown that parameter robustness can be very low for a variety of basic plan structures and that none of these plan structures dominate all others in terms of their robustness properties. Furthermore, additional exercise conditions, either absolute or relative, have only a small impact on a plan's robustness. The same applies for the joint exercise of sub-plans in comparison with a separate exercise. The interplay between caps and the length of the vesting period, however, can have strong effects.

Based on our results, we have investigated and shown how to improve robustness by combining certain design elements of stock option plans. An important decision is to 
lengthen the vesting period and to grant European options instead of American or Bermudan options. As a result, the effective lifetime of the option becomes known, which avoids all complications arising from an unknown exercise behavior of the option holders. The use of European options also improves numerical tractability since usually analytical pricing formulas are available for European style options. Moreover, if the effective lifetime of the option is known, one can use the appropriate interest rate for this period and as a consequence, parameter robustness with respect to interest rates becomes much less important.

Two other important input parameters are the dividend yield and the volatility. As far as the dividend sensitivity is concerned, this can be avoided through dividend protection. Although non-robustness with respect to volatility is relatively more difficult to handle, we have shown that the use of caps can often lead to vega-neutral plans and we have provided solutions for the corresponding strike prices. In conclusion, we believe that almost all of the major issues associated with non-robustness can be resolved by using a proper plan design. Thus, with an appropriate plan design, we can be optimistic about the reliable accounting valuation of stock option plans.

Of course, robustness cannot be the only criterion that a stock option plan should fulfill. There are at least two other essential criteria: incentives to create shareholder value and transparency. Both of these criteria are strongly interrelated with robustness. With respect to the incentive effects of robust stock option plans, we observe that their stock price sensitivity is still very reasonable and at least as high as for an all-stock compensation plan. We have to stress, however, that there can be a trade-off between robustness and incentive effects and that we do not make any attempt in this paper to suggest a plan that leads to a trade-off that is optimal in any sense. In practice, incentive effects of stock option plans can depend on, for example, the competitiveness of the industry, the degree of agency problems, or the extent of operational and financial leverages. Therefore, optimal plan designs might be different for different firms and might also be quite non-robust.

The types of robust plans that we have constructed in this paper are also particularly transparent ones that consist of a few basic building blocks. It is this kind of transparency that allows us to achieve robustness, since otherwise we would not be able to solve analytically for a vega-neutral plan design. Our building block approach also has advantages with respect to particular requirements for good corporate governance. It is quite easy to include both absolute and relative performance targets in one plan, while maintaining a plan's robustness and transparency. For example, one could grant one sub-plan with a premium option and one sub-plan with an indexed option. Both sub-plans could be designed separately as robust plans.

Finally, we believe that robustness of stock option plans is in itself an element of good corporate governance, as it could make it much harder for managers to understate the values of their compensation packages. It would be an interesting avenue for further research to devise empirical tests of this hypothesis. In this respect, one could analyze, for example, how robustness of compensation packages is related to certain indicators of good corporate governance. Another interesting empirical issue is whether there is a trend in actual compensation packages to be more robust, which could indicate an enforcement of robust plan designs by market discipline. If financial markets see the robustness of a compensation package as an important aspect of good corporate governance, robustness could finally be positively related to a firm's market value. An analysis of robustness properties, as presented in this paper, could provide the basis for this future empirical work. 
Open Access This article is distributed under the terms of the Creative Commons Attribution Noncommercial License which permits any noncommercial use, distribution, and reproduction in any medium, provided the original author(s) and source are credited.

\section{Appendix 1}

All valuations done in Sects. 2 and 3 and of this paper use the same three-dimensional additive tree model with equal up and down factors. ${ }^{30}$ Although simpler models exist for some options that we consider, the use of a common framework has the advantage that no price differences can result from different convergence properties and approximation errors of different models.

The concrete model choice was made for three reasons. ${ }^{31}$ Firstly, we need a threedimensional tree to price options with relative performance targets, since their prices depend on two underlyings: the stock price and the value of the reference index. Secondly, the use of an additive tree with equal up and down factors simplifies the valuation of barrier options, like the relative performance vested option. Finally, additive trees (for log prices) have better convergence and approximation properties than comparable multiplicative trees (for prices).

The model is constructed as follows. Assume that the $\log$ share price $\ln S$ and the $\log$ index level ln $P$ follow two correlated generalized Wiener processes under the risk-neutral measure, as given in Eqs. 4 and 5, where $r$ is the risk-free interest rate, $q_{S}$ and $q_{P}$ denote the dividend yields, $\sigma_{S}$ and $\sigma_{P}$ the volatilities, and $\rho_{S P}$ the correlation between instantaneous changes in the Wiener processes $z_{S}$ and $z_{P}$.

$$
\begin{aligned}
& d \ln S=\left(r-q_{S}-\sigma_{S}^{2} / 2\right) d t+\sigma_{S} d z_{S} \\
& d \ln P=\left(r-q_{P}-\sigma_{P}^{2} / 2\right) d t+\sigma_{P} d z_{P}
\end{aligned}
$$

The above processes are approximated by a tree model as follows: We use the up factors $h_{S}=\sigma_{S} \sqrt{\Delta t}$ and $h_{P}=\sigma_{P} \sqrt{\Delta t}$, respectively, where $\Delta t$ is the step length. Down factors are just equal to up factors but with opposite signs. These up and down factors are finally combined with risk neutral probabilities for all possible combinations of up and down moves, which are given in Eqs. 6 below

$$
\begin{aligned}
& p_{u u}=\left(h_{S} h_{P}+h_{P} v_{S} \Delta t+h_{S} v_{P} \Delta t+\rho_{S P} \sigma_{S} \sigma_{P} \Delta t\right) /\left(4 h_{S} h_{P}\right), \\
& p_{u d}=\left(h_{S} h_{P}+h_{P} v_{S} \Delta t-h_{S} v_{P} \Delta t-\rho_{S P} \sigma_{S} \sigma_{P} \Delta t\right) /\left(4 h_{S} h_{P}\right), \\
& p_{d u}=\left(h_{S} h_{P}-h_{P} v_{S} \Delta t+h_{S} v_{P} \Delta t-\rho_{S P} \sigma_{S} \sigma_{P} \Delta t\right) /\left(4 h_{S} h_{P}\right), \\
& p_{d d}=\left(h_{S} h_{P}-h_{P} v_{S} \Delta t-h_{S} v_{P} \Delta t+\rho_{S P} \sigma_{S} \sigma_{P} \Delta t\right) /\left(4 h_{S} h_{P}\right),
\end{aligned}
$$

where $v_{S}$ and $v_{P}$ denote the risk-neutral drift rates of $\ln S$ and $\ln P$.

The above tree specification needs a slight modification to simplify the valuation of relative performance vested options, which are barrier options with stochastic outside barrier. In fact, the stochastic outside barrier can be transformed into a fixed outside barrier if we consider the process $\ln I=\ln S-\ln P$. Since $\ln I$ provides the outperformance of the stock, a certain level of outperformance can be expressed as a fixed barrier of the ln $I$ process.

The corresponding stochastic differential equation becomes

\footnotetext{
30 An alternative would be the trinomial model by Chang and Lin (2010).

31 See also Clewlow and Strickland (2004), p. 44-46.
} 


$$
d \ln I=\left(-q_{S}+q_{P}-\sigma_{S}^{2} / 2+\sigma_{P}^{2} / 2\right) d t+\sqrt{\sigma_{S}^{2}+\sigma_{P}^{2}=2 \sigma_{S} \sigma_{P} \rho_{S P} d z_{I}}
$$

where $z_{I}$ is a standard Wiener process whose changes have an instantaneous correlation equal to $\rho_{S I}=\left(\sigma_{S}-\sigma_{P} \rho_{S P}\right) / \sqrt{\sigma_{S}^{2}+\sigma_{P}^{2}-2 \sigma_{S} \sigma_{P} \rho_{S P}}$ with changes of $z_{S}$.

When we use the processes from Eqs. 4 and 7 to construct a three-dimensional tree in the same manner as described above, all kinds of options that we consider can be easily valued by means of recursive algorithms. ${ }^{32}$

\section{Appendix 2}

This appendix provides some additional information about the similarity of the traditional option, the relative performance vested option, and the absolute performance vested option with respect to their robustness properties. For a broad range of parameter values, we find that the traditional option and the relative performance vested option have almost identical prices, which is due to the fact that the vesting condition of the relative performance vested option is almost always fulfilled. Of course, this feature translates directly into almost identical robustness properties of the two options. When comparing the traditional option with the absolute performance vested option for different parameter combinations, prices can be quite different, however, sensitivities are again very similar. As an example, Table 4 below provides the relative differences in the sensitivity measures "vega", "dividend yield sensitivity", and "rho" for some set of parameter combinations.

\section{Appendix 3}

Let us first consider the premium option with strike price $X=S_{0} \mathrm{e}^{r T}$ Substituting this strike price into Eq. 2, we obtain the following expression for the strike price $Y$ of the short call: $Y=S_{0} \mathrm{e}^{\left(r+\sigma^{2}\right) T}$. The delta of a portfolio of one call option long with strike price $X$ and one call option short with strike price $Y$ equals:

$$
\begin{aligned}
& N\left(d_{1}^{x}\right)-N\left(d_{1}^{y}\right), \text { with } \\
& d_{1}^{x}=\frac{\ln \left(S_{0} / X\right)+\left(r+\sigma^{2} / 2\right) T}{\sigma \sqrt{T}}=\frac{\ln \left(\mathrm{e}^{-r T}\right)+\left(r+\sigma^{2} / 2\right) T}{\sigma \sqrt{T}}=\frac{1}{2} \sigma \sqrt{T}, \quad \text { and } \\
& d_{1}^{y}=\frac{\ln \left(S_{0} / Y\right)+\left(r+\sigma^{2} / 2\right) T}{\sigma \sqrt{T}}=\frac{\ln \left(\mathrm{e}^{-\left(r+\sigma^{2}\right) T}\right)+\left(r+\sigma^{2} / 2\right) T}{\sigma \sqrt{T}}=-\frac{1}{2} \sigma \sqrt{T}
\end{aligned}
$$

Since $N(-\sigma \sqrt{T} / 2)=1-N(\sigma \sqrt{T} / 2)$, we obtain

$$
N\left(d_{1}^{x}\right)-N\left(d_{1}^{y}\right)=2 N(\sigma \sqrt{T} / 2)-1
$$

Next consider the value of the portfolio of the two options:

$\overline{32}$ For such algorithms in the case of barrier options see e.g. Clewlow and Strickland (2004). 
Table 4 Differences in robustness between the absolute performance vested option and the traditional option

\begin{tabular}{|c|c|c|c|c|c|c|c|c|c|}
\hline \multirow[b]{2}{*}{ Vol.IDiv. } & \multicolumn{3}{|c|}{ int. rate $=2 \%$} & \multicolumn{3}{|c|}{ int. rate $=3 \%$} & \multicolumn{3}{|c|}{ int. rate $=4 \%$} \\
\hline & $1 \%$ & $2 \%$ & $3 \%$ & $1 \%$ & $2 \%$ & $3 \%$ & $1 \%$ & $2 \%$ & $3 \%$ \\
\hline \multicolumn{10}{|c|}{ Vega } \\
\hline $15 \%$ & $0.2 \%$ & $0.2 \%$ & $-0.1 \%$ & $-1.8 \%$ & $1.2 \%$ & $0.2 \%$ & $-5.5 \%$ & $-1.2 \%$ & $1.0 \%$ \\
\hline $25 \%$ & $0.3 \%$ & $0.2 \%$ & $0.0 \%$ & $0.0 \%$ & $0.4 \%$ & $0.2 \%$ & $-0.4 \%$ & $0.3 \%$ & $0.4 \%$ \\
\hline $40 \%$ & $0.2 \%$ & $0.2 \%$ & $0.1 \%$ & $0.2 \%$ & $0.2 \%$ & $0.2 \%$ & $0.2 \%$ & $0.3 \%$ & $0.2 \%$ \\
\hline \multicolumn{10}{|c|}{ Dividend yield sensitivity } \\
\hline $15 \%$ & $-0.8 \%$ & $-4.3 \%$ & $-2.9 \%$ & $2.2 \%$ & $-5.8 \%$ & $-3.5 \%$ & $3.5 \%$ & $1.4 \%$ & $-5.0 \%$ \\
\hline $25 \%$ & $-1.4 \%$ & $-1.9 \%$ & $-1.5 \%$ & $0.4 \%$ & $-2.5 \%$ & $-1.6 \%$ & $0.8 \%$ & $-0.9 \%$ & $-2.0 \%$ \\
\hline $40 \%$ & $-0.8 \%$ & $-0.8 \%$ & $-0.7 \%$ & $-0.3 \%$ & $-0.9 \%$ & $-0.7 \%$ & $0.0 \%$ & $-0.7 \%$ & $-0.8 \%$ \\
\hline \multicolumn{10}{|c|}{ Rho } \\
\hline $15 \%$ & $1.3 \%$ & $-1.8 \%$ & $-1.0 \%$ & $4.4 \%$ & $-2.7 \%$ & $-1.1 \%$ & $6.0 \%$ & $3.7 \%$ & $-2.6 \%$ \\
\hline $25 \%$ & $-0.1 \%$ & $-0.7 \%$ & $-0.4 \%$ & $1.5 \%$ & $-1.2 \%$ & $-0.5 \%$ & $1.9 \%$ & $0.5 \%$ & $-0.9 \%$ \\
\hline $40 \%$ & $-0.1 \%$ & $-0.1 \%$ & $0.0 \%$ & $0.4 \%$ & $-0.3 \%$ & $0.0 \%$ & $0.7 \%$ & $0.0 \%$ & $-0.1 \%$ \\
\hline
\end{tabular}

This table shows the percentage differences between the sensitivity measures ("vega", "dividend yield sensitivity", and "rho") of the absolute performance vested option and the traditional option for different combinations of volatility, dividend yield, and risk-free interest rate ([absolute performance vested - traditional]/ absolute performance vested). The absolute performance vested option has a strike price that is $30 \%$ above the stock price and both options have a time to maturity of 8 years and a vesting period of 2 years

Table 5 Differences in robustness between two sub-plans that must be exercised jointly and two sub-plans that can be exercised separately

\begin{tabular}{|c|c|c|c|c|c|c|c|c|c|}
\hline \multirow[b]{2}{*}{ Vol.IDiv. } & \multicolumn{3}{|c|}{ int. rate $=2 \%$} & \multicolumn{3}{|c|}{ int. rate $=3 \%$} & \multicolumn{3}{|c|}{ int. rate $=4 \%$} \\
\hline & $1 \%$ & $2 \%$ & $3 \%$ & $1 \%$ & $2 \%$ & $3 \%$ & $1 \%$ & $2 \%$ & $3 \%$ \\
\hline \multicolumn{10}{|c|}{ Vega } \\
\hline $15 \%$ & $-0.4 \%$ & $2.7 \%$ & $4.9 \%$ & $-0.1 \%$ & $2.0 \%$ & $4.6 \%$ & $-0.1 \%$ & $3.3 \%$ & $5.0 \%$ \\
\hline $25 \%$ & $0.1 \%$ & $1.4 \%$ & $3.1 \%$ & $0.0 \%$ & $1.1 \%$ & $2.8 \%$ & $-0.1 \%$ & $1.3 \%$ & $2.6 \%$ \\
\hline $40 \%$ & $0.1 \%$ & $0.5 \%$ & $1.0 \%$ & $0.0 \%$ & $0.4 \%$ & $0.9 \%$ & $0.1 \%$ & $0.4 \%$ & $0.8 \%$ \\
\hline \multicolumn{10}{|c|}{ Dividend yield sensitivity } \\
\hline $15 \%$ & $1.9 \%$ & $7.5 \%$ & $9.4 \%$ & $2.0 \%$ & $6.7 \%$ & $9.2 \%$ & $2.6 \%$ & $6.1 \%$ & $7.7 \%$ \\
\hline $25 \%$ & $1.5 \%$ & $3.9 \%$ & $4.6 \%$ & $1.5 \%$ & $3.5 \%$ & $4.5 \%$ & $2.1 \%$ & $2.6 \%$ & $4.0 \%$ \\
\hline $40 \%$ & $0.9 \%$ & $1.5 \%$ & $1.6 \%$ & $0.9 \%$ & $1.5 \%$ & $1.7 \%$ & $0.9 \%$ & $1.3 \%$ & $1.7 \%$ \\
\hline \multicolumn{10}{|c|}{ Rho } \\
\hline $15 \%$ & $1.8 \%$ & $8.2 \%$ & $8.3 \%$ & $0.1 \%$ & $1.7 \%$ & $7.0 \%$ & $0.0 \%$ & $-2.3 \%$ & $2.5 \%$ \\
\hline $25 \%$ & $3.6 \%$ & $5.0 \%$ & $5.5 \%$ & $0.3 \%$ & $2.3 \%$ & $4.5 \%$ & $-0.3 \%$ & $-1.0 \%$ & $2.8 \%$ \\
\hline $40 \%$ & $2.6 \%$ & $2.6 \%$ & $2.3 \%$ & $0.6 \%$ & $1.9 \%$ & $2.2 \%$ & $-0.6 \%$ & $0.8 \%$ & $1.9 \%$ \\
\hline
\end{tabular}

This table shows the percentage differences between the sensitivity measures ("vega", "dividend yield sensitivity", and "rho") of two sub-plans that must be exercised jointly and two sub-plans that can be exercised separately for different combinations of the stock's return volatility, the stock's dividend yield, and the risk-free interest rate ([joint exercise - separate exercise]/joint exercise). The two sub-plans are a traditional option and an indexed option. The reference index has a volatility of $15 \%$ and a dividend yield of $2 \%$ p.a.; the correlation between stock returns and index returns equals 0.7 . Both options have a time to maturity of 8 years and a vesting period of 2 years 


$$
\begin{aligned}
& C_{x}-C_{y}=\left(S_{0} N\left(d_{1}^{x}\right)-X \mathrm{e}^{-r T} N\left(d_{2}^{x}\right)\right)-\left(S_{0} N\left(d_{1}^{y}\right)-Y \mathrm{e}^{-r T} N\left(d_{2}^{y}\right)\right), \quad \text { with } \\
& d_{2}^{x}=d_{1}^{x}-\sigma \sqrt{T}=-\frac{1}{2} \sigma \sqrt{T}, \quad \text { and } \\
& d_{2}^{y}=d_{1}^{y}-\sigma \sqrt{T}=-\frac{3}{2} \sigma \sqrt{T}
\end{aligned}
$$

Using the appropriate values for $N\left(d_{1}^{x}\right)-N\left(d_{1}^{y}\right), X, Y, d_{2}^{x}$, and $d_{2}^{y}$, the portfolio value in Eq. 10 becomes:

$$
\begin{array}{r}
S_{0}(2 N(\sigma \sqrt{T} / 2)-1)-S_{0}\left(N\left(d_{2}^{x}\right)-\mathrm{e}^{\sigma^{2} T} N\left(d_{2}^{y}\right)\right) \\
\quad=S_{0}\left(3 N(\sigma \sqrt{T} / 2)-2+\mathrm{e}^{\sigma^{2} T} N(-3 \sigma \sqrt{T} / 2)\right)
\end{array}
$$

In the next step, we have to adjust the number of options in order to obtain a standardized portfolio value equal to the share price in order to facilitate comparisons with a compensation package that consists of one share of stock. To achieve this, we have to divide $S_{0}$ by the expression from Eq. 11, which delivers the required number of capped call options in the (standardized) portfolio. Finally, if this number is multiplied by the delta of a single capped call as given in Eq. 9, we obtain the following standardized delta that we require:

$$
\text { Delta }=\frac{2 N\left(\frac{1}{2} \sigma \sqrt{T}\right)-1}{3 N\left(\frac{1}{2} \sigma \sqrt{T}\right)-2+\mathrm{e}^{\sigma^{2} T} N\left(-\frac{3}{2} \sigma \sqrt{T}\right)}
$$

A completely analogous derivation is possible for the indexed option. The only differences are the use of an at-the-money option, i.e., a (normalized) index level that equals the current share price, and the use of the appropriate valuation formula for exchange options. These two modifications exactly offset each other such that the resulting formula is identical to Eq. 12. However, the variance $\sigma^{2}$ does no longer refer to the stock return variance, but to the stock return variance plus the index return variance minus two times the covariance.

Next consider the limiting behavior of delta when either $\sqrt{T}$ or $\sigma$ go to infinity. Then the numerator of delta in Eq. 12 goes to one. Also the first part of the denominator $\left(3 N\left(\frac{1}{2} \sigma \sqrt{T}\right)-2\right)$ goes to one. Thus, what remains to determine is the limit of the second part of the denominator, which can be written as

$$
\frac{N\left(-\frac{3}{2} \sigma \sqrt{T}\right)}{\mathrm{e}^{-\sigma^{2} T}}
$$

Using de l'Hospital's rule, the above ratio has the same limit as the following ratio:

$$
\frac{-\frac{3}{2} N^{\prime}\left(-\frac{3}{2} \sigma \sqrt{T}\right)}{-2 \sigma \sqrt{T} \mathrm{e}^{-\sigma^{2} T}}=\frac{-\frac{3}{2} \frac{1}{\sqrt{2 \pi}} \mathrm{e}^{-\frac{9}{4} \sigma^{2} T}}{-2 \sigma \sqrt{T} \mathrm{e}^{-\sigma^{2} T}}=\frac{3}{4 \sqrt{2 \pi} \sigma \sqrt{T}} \mathrm{e}^{-\frac{5}{4} \sigma^{2} T}
$$

As the last expression in Eq. 14 shows, the ratio goes to zero if either $\sigma$ or $\sqrt{T}$ go to infinity. This result implies that delta goes to one.

Finally, consider the limit of delta for either $\sigma$ or $\sqrt{T}$ going to zero. Since both the numerator and the denominator in Eq. 12 go to zero, we have to apply de l'Hospital's rule again. Taking derivatives in the numerator and denominator, we obtain 


$$
\frac{N^{\prime}\left(\frac{1}{2} \sigma \sqrt{T}\right)}{\frac{3}{2} N^{\prime}\left(\frac{1}{2} \sigma \sqrt{T}\right)-\frac{3}{2} N^{\prime}\left(-\frac{3}{2} \sigma \sqrt{T}\right) \mathrm{e}^{\sigma^{2} T}+2 \sigma \sqrt{T} \mathrm{e}^{\sigma^{2} T} N\left(-\frac{3}{2} \sigma \sqrt{T}\right)}
$$

For either $\sigma \rightarrow 0$ or $\sqrt{T} \rightarrow 0$ the numerator of the ratio (15) approaches $1 / \sqrt{2 \pi}$ and the denominator approaches zero. Therefore, the limit of delta is infinity.

\section{References}

Ammann M, Seiz R (2004) Valuing employee stock options: does the model matter? Financial Anal J 60(5):21-34

Arnold MC, Gillenkirch RM (2005) Stock options and dividend protection. J Inst Theor Econ 16:453-471

Bakshi G, Cao C, Chen Z (1997) Empirical performance of alternative option pricing models. J Finance 52:2003-2049

Bebchuk LA, Fried JM (2003) Executive compensation as an agency problem. J Econ Perspect 17:71-92

Bebchuk LA, Fried JM, Walker DI (2002) Managerial power and rent extraction in the design of executive compensation. Univ Chicago Law Rev 69:751-846

Bettis JC, Bizjak JM, Lemmon ML (2005) Exercise behavior, valuation, and the incentive effects of employee stock options. J Financ Econ 76:445-470

Bettis JC, Bizjak JM, Coles J, Kalpathy S (2010) Stock and option grants with performance-based vesting conditions. Rev Financ Stud 23:3849-3888

Brenner M, Sundaram RK, Yermack D (2000) Altering the terms of executive stock options. J Financ Econ 57:103-128

Brisley N (2006) Executive stock options: early exercise provision and risk-taking incentives. J Finance 61:2487-2509

Brisley N, Anderson CK (2008) Employee stock option valuation with an early exercise boundary. Financ Anal J 64(4):88-100

Brooks R, Chance D, Cline BN (2007) Private information and the exercise of executive stock options. Working paper

Câmara A (2001) The pricing of relative performance based incentives for executive compensation. J Bus Finance Acc 28:1149-1188

Carpenter JN (1998) The exercise and valuation of executive stock options. J Financ Econ 48:127-158

Chang CC, Lin JB (2010) The valuation of multivariate contingent claims under transformed trinomial approaches. Rev Quant Finance Account 34:23-36

Chen RR, Lee CF (2009) Empirical performance of the constant elasticity variance option pricing model. Rev Pac Basin Financ Mark Policies 12:177-217

Clewlow L, Strickland C (2004) Implementing derivatives models. Wiley, Chichester

Core JE, Guay WR, Larcker DF (2003) Executive equity compensation and incentives: a survey. Econ Policy Rev 9:27-55

Cvitanić J, Wiener Z, Zapatero F (2008) Analytic pricing of employee stock options. Rev Financ Stud 21:683-724

Dybvig PH, Loewenstein M (2003) Employee reload options: pricing, hedging and optimal exercise. Rev Financ Stud 16:145-171

Feltham GE, Wu MGH (2001) Incentive efficiency of stock versus options. Rev Account Stud 6:7-28

Fenn GW, Liang N (2001) Corporate payout policy and managerial stock incentives. J Financ Econ 60:45-72

Hall BJ, Murphy KJ (2003) The trouble with stock options. J Econ Perspect 17:49-70

Hemmer T, Matsunaga S, Shevlin T (1996) The influence of risk diversification on early exercise of employee stock options by executive officers. J Account Econ 21:45-68

Hemmer T, Matsunaga S, Shevlin T (1998) Optimal exercise and value of reload options. J Account Res 36:231-255

Hemmer T, Kim O, Verrecchia RE (1999) Introducing convexity into optimal compensation contracts. J Account Econ 28:307-327

Heynen R, Kat H (1994) Crossing barriers. Risk 7(6):46-51

Huddart S, Lang M (1996) Employee stock option exercises: an empirical analysis. J Account Econ 21:5-43

Hull JC (2009) Options, futures and other derivatives. Pearson, Prentice Hall, Upper Saddle River

Hull JC, White A (2004) How to value employee stock options. Financ Anal J 60(1):114-119 
Ikäheimo S, Kuosa N, Puttonen V (2006) The true and fair view of executive stock option valuation. Eur Account Rev 15:351-366

Jaggi B, Winder JP, Lee CF (2010) Is there a future for fair value accounting after the 2008-2009 financial crisis? Rev Pac Basin Financ Mark Policies 13:469-493

Johnson SA, Tian YS (2000a) The value and incentive effects of nontraditional executive stock option plans. J Financ Econ 57:3-34

Johnson SA, Tian YS (2000b) Indexed executive stock options. J Financ Econ 57:35-64

Kulatilaka N, Markus AJ (1994) Valuing employee stock options. Financ Anal J 50(6):46-56

Lambert RA, Lanen WN, Larcker DF (1989) Executive stock option plans and corporate dividend policy. J Financ Quant Anal 24:409-425

Margrabe W (1978) The value of an option to exchange one asset for another. J Finance 33:177-186

Regierugskommission Deutscher Corporate Governance Kodex (ed.) (2005) German Corporate Governance Code

Rubinstein M (1995) On the accounting valuation of employee stock options. J Deriv 3(1):8-24

Sautner Z, Weber M (2011) Corporate governance and the design of stock option contracts. Working paper Smith CW, Stulz RM (1985) The determinants of firms' hedging policies. J Financ Quant Anal 20:391-404

Yang JT, Carleton WT (2010) Repricing of executive stock options. Rev Quant Finance Account (Online first $^{\mathrm{TM}}, 27$ June 2010) 